2013

\title{
A Microfluidic Anti-Factor Xa Assay Device for Point-of-Care Monitoring of Anticoagulation Therapy
}

\author{
Leanne F. Harris \\ Technological University Dublin, leanne.harris@tudublin.ie \\ Paul Rainey \\ Queen's University Belfast \\ Vanessa Castro-Lopez \\ CIC microGUNE
}

See next page for additional authors

Follow this and additional works at: https://arrow.tudublin.ie/scschbioart

Part of the Biology Commons

\section{Recommended Citation}

Harris, L. (2013) A microfluidic anti-Factor Xa assay device for point-of-care monitoring of anticoagulation therapy. Analyst 2013 Sep 7;138(17):4769-76. doi:10.1039/c3an00401e

This Article is brought to you for free and open access by the School of Biological Sciences at ARROW@TU Dublin. It has been accepted for inclusion in Articles by an authorized administrator of ARROW@TU Dublin. For more information, please contact arrow.admin@tudublin.ie, aisling.coyne@tudublin.ie,gerard.connolly@tudublin.ie. Funder: Enterprise Ireland

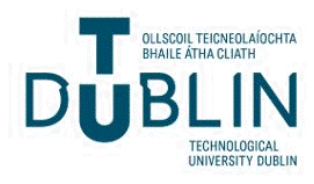




\section{Authors}

Leanne F. Harris, Paul Rainey, Vanessa Castro-Lopez, James S. O'Donnell, and Anthony J. Killard 


\title{
A microfluidic anti-Factor Xa assay device for point-of-care monitoring
}

\section{of anticoagulation therapy ${ }_{\dagger}^{\dagger}$}

\author{
Leanne F. Harris ${ }^{a}$, Paul Rainey ${ }^{b}$, Vanessa Castro-López ${ }^{c}$, James S. O’Donnell ${ }^{d}$, and Anthony J. Killard ${ }^{a, e}$ \\ Received (in $X X X, X X X) X$ th $X X X X X X X X X 20 X X$, Accepted $X$ th $X X X X X X X X X 20 X X$ \\ ${ }_{5}$ DOI: 10.1039/b000000x
}

The development of new point-of-care coagulation assay devices is necessary due to the increasing number of patients requiring longterm anticoagulation in addition to the desire for appropriate, targeted anticoagulant therapy and a more rapid response to optimization of treatment. However, the majority of point-of-care devices currently available for hemostasis testing rely on clot-based endpoints which are variable and unreliable and are limited to measuring only certain portions of the coagulation pathway. There is a need for the 10 introduction of point-of-care devices that can execute a broader range of tests; for example, the diagnosis of factor-specific diseases, as well as more reliable assays of anticoagulant status, particularly in response to the emergence of new anticoagulant drugs. Here we present a novel fluorescence-based anti-Factor Xa (FXa) microfluidic assay device for monitoring the effect of anticoagulant therapy at the point-of-care. The device is a disposable, laminated polymer microfluidic strip fabricated from a combination of hydrophobic and hydrophilic cyclic polyolefins to allow reagent deposition as well as allowing effective capillary fill. An immobilized FXa fluorogenic 15 substrate was allowed to interact with $10 \mu \mathrm{l}$ of a plasma/anticoagulant/exogenous FXa mixture within the microfluidic strip in a timecontrolled manner. The activity of uncomplexed FXa was measured with excitation at $342 \mathrm{~nm}$ and emission at $440 \mathrm{~nm}$. The device was capable of measuring unfractionated and low molecular weight heparins from 0 to $0.8 \mathrm{U} / \mathrm{ml}$ within $60 \mathrm{~s}(\mathrm{CV}<10 \%)$. The device also correlated well with both chromogenic and fluorogenic plate-based assays.

\section{${ }_{20}$ Introduction}

Arterial and venous thromboembolism remain two of the most frequent causes of morbidity and mortality worldwide. ${ }^{1}$ Blood clotting disorders such as these have long been treated using anticoagulant drugs such as warfarin and heparin, with newer,

25 more predictable drugs such as factor $\mathrm{Xa}(\mathrm{FXa})$ and thrombin inhibitors now available. The administration of anticoagulant therapy is carefully monitored due to the potential adverse effects associated with over- or under-dosing. Traditional tests used for monitoring warfarin and heparin include clot-based assays such 30 as the prothrombin time (PT) and activated partial thromboplastin time (aPTT) tests. ${ }^{2}$ These assays were traditionally executed in the central diagnostic laboratory on automated coagulation analysers, but have since been adapted to small, benchtop analysers, as well as handheld monitors for use at the point-of35 care. Examples of such devices include the HemoSense INRatio monitor (Hemosense Inc., USA) for PT/INR home-testing, as well as the i-STAT (Abbott, USA) and Hemochron ${ }^{\circledR}$ analysers (ITC, USA) that can execute a range of clotting assays at the bench or bedside such as the PT, aPTT or ACT (activate clotting 40 time).

Traditional anticoagulant drugs such as heparin have proven extremely effective. However, unfractionated heparin (UFH) is derived from animal sources such as porcine intestine and is highly variable in its molecular weight. ${ }^{3}$ This has unpredictable 45 effects in its anticoagulant properties and so it must be closely monitored using clot-based assays such as aPTT and ACT.,
New anticoagulant drugs such as low molecular weight heparins (LMWHs) have defined pharmacokinetics and pharmacodynamics. Such drugs preferably target FXa rather than so thrombin (FIIa) in the coagulation cascade, but traditional clotting assays are based on the measurement of thrombin formation and are not suitable for monitoring these new drugs. Other assays such as the anti-Factor Xa (anti-FXa) assay have been developed to measure the effect of such drugs. The anti-FXa 55 assay operates via the addition of exogenous FXa to a plasma sample from a patient treated with an anticoagulant drug. Plasma contains antithrombin (AT) which binds to coagulation factors such as thrombin and $\mathrm{FXa}$, so inhibiting their procoagulant function. ${ }^{6}$ However, anticoagulant drugs such as heparin bind to ${ }_{60} \mathrm{AT}$ and significantly increase binding affinity for both thrombin and $\mathrm{FXa}^{2}$ In addition, the high molecular weight of UFH stabilizes a ternary complex of AT, thrombin and heparin. Thus, in the presence of these anticoagulant drugs, the availability of free thrombin and FXa is significantly reduced in a dose${ }_{65}$ dependent manner, with a significant impact on thrombin generation. However, the LMWHs do not form stable ternary structures with AT and thrombin and so their antithrombin activity is substantially reduced, while their anti-FXa activity remains significant. ${ }^{7}$ Having been complexed with AT and 70 anticoagulant drug, the concentration of free FXa is reduced and this can be titrated using a suitable substrate which is selectively cleaved by the serine protease activity of FXa. Pentapeptide substrates with chromophores for colorimetric assays are in widespread use. ${ }^{8,2}$ Unfortunately, absorbance-based assays are 75 more prone to interference from blood and plasma. Recently, 
fluorogenic substrates have been employed as fluorescent labels which are inherently more sensitive than colorimetric substrates, making these suitable labels in miniaturized diagnostic devices. ${ }^{9,10}$

While clot-based assays for PT, aPTT and ACT have been developed for the point-of-care, no such devices exist for the performance of anti-FXa assays. With the increasing use of LMWHs, as well as the development of other drugs such as direct anti-Xa inhibitors (e.g Rivaroxaban and Apixaban), the demand

10 for such screening assays will increase. In addition, there is a major push for the screening of all individuals presenting upon emergency to be screened for their thrombotic risk profile, which is driving demand for development of point-of-care technologies in this area. ${ }^{11,12}$

15 Current advances in point-of-care devices are often the result of microfluidic and microsystems technologies which aim to deliver rapid results, enhanced sensitivity and specificity on lowcost, portable miniaturized devices. ${ }^{13,14}$ The development of a microfluidic device that uses optical detection such as

20 fluorescence or absorbance requires the careful selection of device substrate materials. Glass has always been favored for optical applications due to its excellent clarity. However, its brittle nature results in processing and handling difficulties. ${ }^{15}$ Other inorganic materials such as silicon and quartz are not ideal 25 for disposable microfluidics due to high material and manufacturing costs. ${ }^{16}$ The use of polymer-based microfluidics has gained in popularity over the last few years with substrates such as cyclic polyolefins (COPs) becoming more widely used in microfabrication. COPs offer many advantages for application to

30 point-of-care devices such as low autofluorescence, high UV transmission, high temperature resistance and chemical inertness. $^{16,17}$ In addition COPs can be modified to create hydrophilic surfaces from their native hydrophobic state which aids in fluid flow and control, without the incorporation of 35 complex pumping systems, which is an important parameter in the design of point-of-care devices.

A fluorogenic anti-FXa assay was previously developed in our laboratory for monitoring heparin therapy in both human calibration plasmas and patient plasmas. ${ }^{9,18}$ In this paper we ${ }_{40}$ present a miniaturized, disposable device incorporating the fluorogenic anti-FXa assay. Data is presented showing that it can be used effectively to monitor heparin anticoagulation (UFH, enoxaparin and tinzaparin) in plasma samples, hence its suitability for application to point-of-care testing.

\section{${ }_{45}$ Experimental}

\section{Reagents}

Water (ACS reagent) and HEPES (minimum 99.5\% titration) were purchased from Sigma-Aldrich (Dublin, Ireland). Filtered HEPES was prepared at a concentration of $0.01 \mathrm{mM}(\mathrm{pH}$ 7.4). A so $100 \mathrm{mM}$ filtered stock solution of $\mathrm{CaCl}_{2}$ from Fluka BioChemika (Buchs, Switzerland) was prepared from a $1 \mathrm{M} \mathrm{CaCl}_{2}$ solution.

The fluorogenic substrate methylsulfonyl-D-cyclohexylalanylglycyl-arginine-7-amino-4-methylcoumarin acetate (Pefafluor ${ }^{\mathrm{TM}}$ FXa) was purchased from Pentapharm (Basel, Switzerland). It 55 was reconstituted in $1 \mathrm{ml}$ of water having a stock concentration of $10 \mathrm{mM}$, aliquoted, covered with aluminum foil to protect from exposure to light, and stored at $-20{ }^{\circ} \mathrm{C}$. Dilutions from $10 \mathrm{mM}$ stock solutions were freshly prepared with $0.01 \mathrm{mM}$ HEPES when required. Purified human FXa (serine endopeptidase; code 60 number: EC 3.4.21.6) was obtained from HYPHEN BioMed (Neuville-Sur-Oise, France) and was reconstituted in $500 \mu \mathrm{l}$ of PCR grade water to give a stock concentration of $4400 \mathrm{nM}$, with subsequent dilutions made with $10 \mathrm{mM}$ HEPES buffer. Unfractionated heparin (UFH) (sodium salt of heparin derived 65 from bovine intestinal mucosa, H0777) was sourced from SigmaAldrich (Dublin, Ireland), Enoxaparin (Clexane $\left.{ }^{\circledR}\right)$ and Tinzaparin (Innohep $\left.{ }^{\circledR}\right)$ were obtained from Sanofi-Aventis (Paris, France) and LEO Pharma (Ballerup, Denmark) respectively. Human pooled plasma was purchased from Helena Biosciences Europe 70 (Tyne and Wear, UK). Lyophilized plasma was reconstituted in 1 $\mathrm{ml}$ of water and left to stabilise for at least $20 \mathrm{~min}$ at room temperature prior to use.

Rolls of $188 \mu \mathrm{m}$ thick cyclic polyolefin polymer (Zeonor ${ }^{\circledR}$ ) were purchased from IBIDI GmbH (Munich, Germany). 75 ARcare ${ }^{\circledR} 9271250 \mu \mathrm{m}$ double sided pressure sensitive adhesive (PSA), BOPP-HY10 and HY10-coated Zeonor were purchased from Adhesives Research (Limerick, Ireland). Sheets of $188 \mu \mathrm{m}$ Zeonor ${ }^{\circledR}$ was treated with a hydrophilic coating from Hydromer Inc. (NJ, USA). Strip materials were cut using a Graphtec Vinyl ${ }_{80}$ Cutter, Model CE5000-40-CRP from Graphtec GB Limited (Wrexham, UK). Contact angle measurements were carried out using an FTA 200 analyser from First Ten Angstroms, Inc. (Virginia, USA).

All fluorescent measurements were carried out at $37^{\circ} \mathrm{C}$ using 85 an Olympus IX81 motorised fluorescent microscope sourced from Olympus Europa GmbH (Hamburg, Germany) housed within an incubation chamber with an attached Hamamatsu Orca ER digital camera, Model C4742-80-12AG from Hamamatsu Photonics (Hertfordshire, UK). Fluorescence was monitored 90 according to the following settings: magnification $\times 10$; excitation at $342 \mathrm{~nm}$ and emission at $440 \mathrm{~nm}$; exposure time of $20 \mathrm{~ms}$. All values of fluorescence are reported as arbitrary fluorescence units (AU). All measurements were analyzed using the Cell^ $\mathrm{R}$ realtime imaging software from Mason Technology (Dublin, Ireland) with 95 subsequent data exportation into Excel, SigmaPlot 8.0, and SPSS 17.0 for analysis.

\section{Microfluidic assay and device}

For final strip assembly, the hydrophobic Zeonor lid (75 mm x 25 $\mathrm{mm}$ ) was bonded to a PSA layer cut with a channel of $50 \mathrm{~mm}$ 100 long x $2 \mathrm{~mm}$ wide, giving a total channel volume of $10 \mu \mathrm{l}$. The Zeonor lid was cut with an elliptical sample inlet of $4 \mathrm{~mm}$ diameter and a rectangular outlet of $4 \times 1.5 \mathrm{~mm}$ to allow air to escape from inside the channel. $2 \mu 1$ of Pefafluor ${ }^{\mathrm{TM}} \mathrm{FXa}$ fluorogenic substrate was deposited with a pipette within the 105 channel as four $0.5 \mu 1$ droplets onto the hydrophobic Zeonor at a distance of $1.5 \mathrm{~mm}$ from the outlet (Fig. 1). Channels with deposited reagents were dried overnight in a glass desiccator with silica at $19^{\circ} \mathrm{C}$ and $10 \% \mathrm{RH}$. After drying, the strips were pressure laminated and sealed with a hydrophilic Zeonor base.

110 All measurements for the fluorogenic anti-FXa assay were carried out in reconstituted citrated human pooled plasma. $4 \mu \mathrm{l}$ of $260 \mathrm{nM}$ FXa were incubated with $6 \mu \mathrm{l}$ of re-calcified plasma (44 $\mu 1$ heparinised plasma $+6 \mu 1100 \mathrm{mM} \mathrm{CaCl}_{2}$ ) for 10 seconds and 
$10 \mu 1$ of this $\mathrm{FXa}$ /plasma mixture was immediately applied to the inlet of the assay strip. Plasma samples were spiked with pharmacologically relevant concentrations $(0-0.8 \mathrm{U} / \mathrm{ml})$ of anticoagulants including UFH, enoxaparin, and tinzaparin, as 5 appropriate.

Detailed experimental protocols on the fluorogenic and chromogenic assay correlations can be found in the Supplementary Experimental Section S-1.

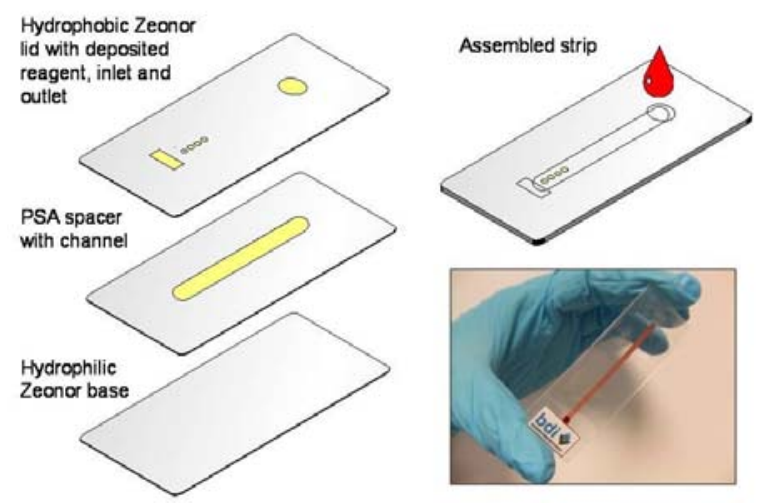

10 Fig. 1. Schematic and photograph of the microfluidic anti-FXa assay device. Strips were assembled from a hydrophobic Zeonor lid containing an inlet and outlet. The single straight channel was cut from PSA which seals the lid and base layers. The base layer was hydrophilic zeonor to allow for capillary fill of the strip. Fluorogenic FXa substrate was 15 deposited onto the hydrophobic lid prior to assembly.

\section{Results and discussion}

While coagulation monitoring devices occupy a large portion of the point-of-care market, there is significant scope for the development and introduction of novel devices, which offer 20 improvements over conventional clotting tests for anticoagulant monitoring. Peptide substrates specific for coagulation proteins such as thrombin and plasmin emerged in the $1960 \mathrm{~s}^{19,20}$, with the first anti-Xa chromogenic assay for heparin monitoring developed in $1976 .{ }^{21}$ The chromogenic anti-FXa assay is now 25 classed by central diagnostic laboratories as the 'gold standard' assay for measuring heparin anticoagulant therapy in plasma samples. However, point-of-care -based anti-Xa assay systems have yet to be developed.

\section{${ }_{30}$ Strip materials characterization and selection}

For the development of point-of-care microfluidic assay devices, polymer-based materials are by far the most widely used due to the low cost of the materials, the range of simple fabrication 35 methodologies available, their inert physical characteristics and good compatibility with biological materials. There are a range of popular polymer materials available such as polycarbonate (PC), polyethylene terephthalate (PET) and polymethylmethacrylate (PMMA). ${ }^{22,23}$ However, such materials do suffer from some 40 disadvantages. For sensitive assays based on fluorescence detection, their high background fluorescence is a problem. An alternative group of polymers with low inherent fluorescence are the cyclic polyolefins. These are now finding widespread use in bioassays in which sensitive fluorescence-based methods are 45 used. These polymers like many others suffer from significant hydrophobicity and so can be challenging when used with liquid biological samples such as blood where capillary flow is required. A range of surface treatments and modifications have been developed to improve the hydrophilicity of these materials and ${ }_{50}$ this has made them viable materials for biodevice development. ${ }^{23}$

A range of transparent polymer materials were initially screened for their background fluorescence characteristics when excited at $342 \mathrm{~nm}$. These were PMMA, PET, Zeonor ${ }^{\circledR}$ and Topas, the latter two being cyclic olefin polymers. Among these, ${ }_{55}$ Zeonor ${ }^{\circledR}$ was found to have the lowest fluorescence (data not shown). However, the hydrophobicity of the Zeonor films was still problematic, preventing good capillary flow. A number of cyclic polyolefins with various hydrophilic surface coatings were analyzed for their auto-fluorescence properties, as well as their 60 water contact angle measurements and capillary fill characteristics when assembled into a simple capillary channel (Fig. 2). While both of the HY10-modified films had excellent contact angles and capillary fill times $\left(7.6^{\circ} \pm 0.7^{\circ}\right.$ and $23 \pm 1 \mathrm{~s}$, respectively) the HY10 surface modification contributed 65 significantly to the background fluorescence $(640.9 \pm 2.3 \mathrm{AU}$, where maximum fluorescence $=4000 \mathrm{AU})$. Unmodified Zeonor exhibited low fluorescence as is well established. However, it showed high contact angles in excess of $100^{\circ}$ and capillary fill times were not recordable as liquid could not flow along the 70 channel, making it unsuitable. The Hydromer-modified Zeonor exhibited comparable fluorescence with unmodified Zeonor of 208.5 $\mathrm{AU}$, as well as having excellent contact angles $\left(17.5^{\circ} \pm\right.$ $\left.0.9^{\circ}\right)$ and capillary fill times $(20.3 \pm 2.1 \mathrm{~s})$.

In circumstances where the deposition of small volumes of 75 aqueous-based reagents is required onto such polymeric surfaces, hydrophilic surfaces result in the deposited material spreading in an unpredictable manner across the surface due to its good wetting properties. Thus, a hybrid hydrophobic/hydrophilic design was proposed which would possess a hydrophobic layer 80 for reagent deposition and a hydrophilic layer to induce capillary flow. Devices assembled using this hybrid approach were composed of materials with fill times of $20.3 \pm 2.1 \mathrm{~s}$, contact angles of $17.5^{\circ} \pm 0.9^{\circ} \mathrm{s}$ and low background fluorescence levels of $208.5 \pm 0.1 \mathrm{AU}$ which were intermediate to either fully 85 hydrophobic or fully hydrophilic devices. Thus, further device development was based on Zeonor and Zeonor modified with Hydromer coating. The final assay device configuration was a three layer laminate strip comprising a $188 \mu \mathrm{m}$ thick hydrophilic Zeonor base to induce capillary flow, a $50 \mu \mathrm{m}$ PSA spacer with 90 channel and a $188 \mu \mathrm{m}$ hydrophobic Zeonor lid for reagent deposition. 


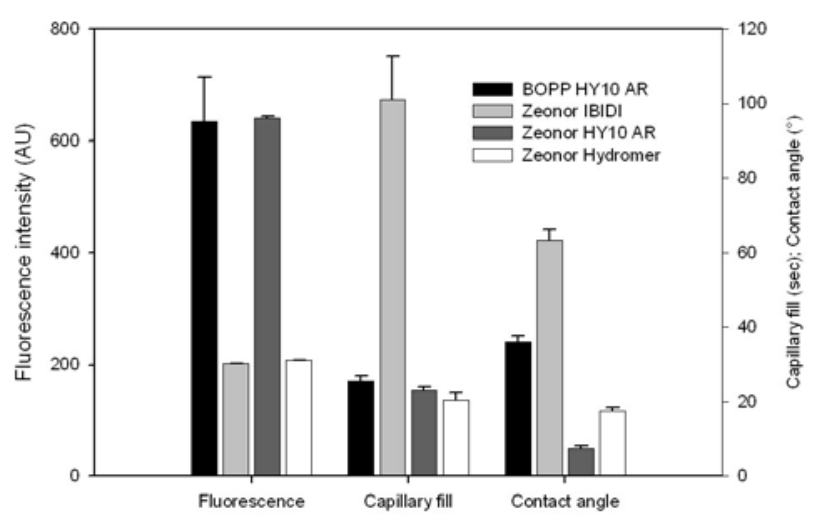

Fig. 2. Evaluation of device materials in terms of their auto-fluorescence, capillary fill times in assembled strip, and water contact angles $(n=3)$.

\section{${ }_{5}$ Assay optimization}

Using a plate-based fluorogenic anti-FXa assay as a guideline ${ }^{9}$, the assay was transferred to and optimized on the strip format. FXa and Pefafluor ${ }^{\mathrm{TM}}$ FXa fluorogenic substrate were titrated 10 within the range of $60-460 \mathrm{nM}$ and $30-180 \mu \mathrm{M}$, respectively. Initial titrations were performed on chip with $\mathrm{FXa}$ and Pefafluor ${ }^{\mathrm{TM}}$ FXa dried onto the Zeonor surface. Fig. 3 shows typical fluorescence response profiles of the strip to different concentrations of Pefafluor ${ }^{\mathrm{TM}} \mathrm{FXa}$ substrate at a FXa 15 concentration of $260 \mathrm{nM}$. This illustrates the conversion of fluorogenic substrate to fluorescent product which is limited by substrate concentration below $120 \mu \mathrm{M}$. After approx. $60 \mathrm{~s}$, all substrate has been converted. It can also be observed that the maximum fluorescence signal that could be achieved with the

20 available instrumentation was approximately 4000 AU which was achieved with substrate concentrations in excess of $60 \mu \mathrm{M}$. To ensure that substrate limitation did not result, a concentration of $150 \mu \mathrm{M}$ was selected.

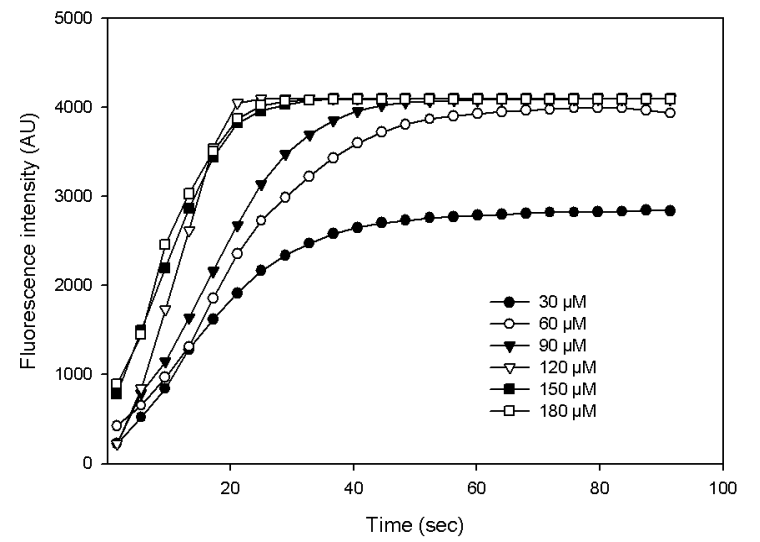

Fig. 3: Typical fluorescence profiles of the anti-Xa assay with $260 \mathrm{nM}$ FXa and concentrations of Pefafluor ${ }^{\mathrm{TM}} \mathrm{FXa}$ from 30 to $180 \mu \mathrm{M}(\mathrm{n}=3)$.

Titrations of FXa concentration were performed, maintaining Pefafluor $^{\mathrm{TM}}$ concentration at $150 \mu \mathrm{M}$ and varying $\mathrm{FXa}$ concentration from 60 to $460 \mathrm{nM}$ at $0,0.5$ and $1 \mathrm{U} / \mathrm{ml}$ heparin
35 (Fig. 4). The effect of heparin on the response of each titration was analyzed and regression analysis was used to determine the optimal concentration of FXa. Regression analysis for 60 and 120 $\mathrm{nM}$ FXa returned $\mathrm{R}^{2}$ values of 0.99 . However, a wider signal range and a higher value at $0 \mathrm{U} / \mathrm{ml}$ was achieved at $260 \mathrm{nM}$ with 40 an $\mathrm{R}^{2}$ value of 0.99 . At higher concentrations of $360 \mathrm{nM}$ and 460 $\mathrm{nM}$ FXa, regression analysis returned lower $\mathrm{R}^{2}$ values of 0.93 and 0.87 , respectively. Final assay concentrations were thus optimized at $150 \mu \mathrm{M}$ fluorogenic substrate and $260 \mathrm{nM}$ FXa and were tested using heparinised plasma samples at $0.25 \mathrm{U} / \mathrm{ml}$ ${ }_{45}$ intervals from 0 to $0.8 \mathrm{U} / \mathrm{ml}$. Good separation was observed between heparin concentrations.

Another important feature of assay and device development was sample volume. The device required $10 \mu \mathrm{l}$ of plasma to execute a measurement, which is in line with point-of-care ${ }_{50}$ devices such as the CoaguCheck (Roche Diagnostics, UK), yet significantly lower than the $50 \mu \mathrm{l}$ sample volume required to perform a test on the Hemochron ${ }^{\circledR}$ systems or the $20 \mu \mathrm{l}$ sample volume required for application to the i-STAT analysers (Abbott, USA) ${ }^{24}$ The fast turnaround time of 60 seconds is also a 55 significant advantage of the anti-FXa fluorogenic point-of-care device.

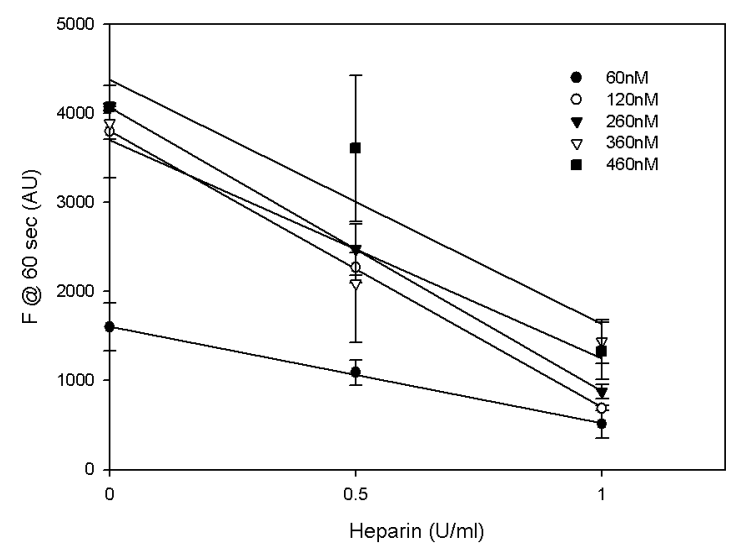

Fig. 4: Fluorescence responses at $60 \mathrm{~s}$ for 60 to $460 \mathrm{nM}$ FXa and $150 \mu \mathrm{M}$ fluorogenic substrate at $0,0.5$ and $1 \mathrm{U} / \mathrm{ml} \mathrm{UFH}(\mathrm{n}=3)$.

$$
60
$$

\section{Optimization of substrate deposition}

One of the most challenging aspects of the development of miniaturized diagnostic devices remains the effective deposition 65 and subsequent resolubilisation of the assay reagents within the microfluidic device. Some aspects of this relate to the process used for deposition and others to the material being deposited. These factors can have a significant impact on assay performance and reproducibility. In the current assay device, four $\mathrm{x} 0.5 \mu \mathrm{l}$ 70 spots of the fluorogenic substrate were deposited in the microfluidic channel close to the measurement chamber. While automated methods of deposition are generally required for mass production to achieve control of volume and positional accuracy, it was found here that manual pipetting achieved reliable and 75 reproducible results with spot diameters of $877 \pm 51 \mu \mathrm{m}$ with CVs of $6 \%(n=10)$, compared to inkjet printed spot diameters of $1094 \pm 155 \mu \mathrm{m}$ with CVs of $14 \%(\mathrm{n}=10)$. 
A range of buffers (10 mM HEPES, $0.01 \mathrm{mM}$ HEPES, StabilCoat buffer, $2 \%$ Tween $20,10 \%$ PEG $3400,1 \%$ Triton X100) were tested for their effect on the dissolution, deposition and drying characteristics of the fluorogenic substrate. The 5 morphology of the dried substrate spots can be seen in Fig. S-1 (A-F). It can immediately be seen that the matrices based on HEPES, StabilCoat and PEG produced uniform spots. However, the mixtures containing surfactant showed spot spreading and irregularity. Both the $10 \mathrm{mM}$ HEPES and StabilCoat buffers 10 showed a classical coffee-ring or doughnut morphology due to the movement of material to the edge of the droplet during drying. The dried polymer could also be seen in the sample containing PEG. However, 0.01 mM HEPES buffer resulted in uniform spots with few defects. Horizontal spot diameters

15 measured on average $845 \mu \mathrm{m} \pm 59 \mu \mathrm{m}(\mathrm{n}=10 ; \mathrm{CV}=6.9 \%)$ and vertical spot diameters measured $877 \mu \mathrm{m} \pm 51 \mu \mathrm{m}(\mathrm{n}=10 ; \mathrm{CV}=$ $5.8 \%)$.

Based on these morphological characteristics and fluorescent assay responses, HEPES buffer was found to be the most suitable 20 matrix for the fluorogenic substrate. The impact of HEPES concentration on the performance of the substrate was further assessed. Three concentrations of HEPES buffer were subsequently tested for optimal performance in the assay using plasma or plasma with $0.5 \mathrm{U} / \mathrm{ml} \mathrm{UFH,} 260 \mathrm{nM}$ FXa and $150 \mu \mathrm{M}$ 25 substrate in 0.01, 0.05, and 0.1 mM HEPES (Fig. S-2). HEPES at $0.01 \mathrm{mM}$ was selected as the optimal concentration as it returned the maximum fluorescence signal at $0 \mathrm{U} / \mathrm{ml}$ heparin and showed the greatest potential signal range with the smallest errors $(1,896$ AU between $0 \mathrm{U} / \mathrm{ml}$ and $0.5 \mathrm{U} / \mathrm{ml}$ ).

30 The effect of temperature on the drying of the fluorogenic substrate was also assessed. Fluorogenic substrate prepared in $0.01 \mathrm{mM}$ HEPES was dried onto the microfluidic devices using a range of temperature and humidity. The most reliable and reproducible method of drying as determined from the 35 morphology of the deposited spots proved to be drying at room temperature, at $10 \% \mathrm{RH}$, in a glass desiccator, which was subsequently adopted for preparation of assay devices.

\section{Anticoagulant calibrations}

40

The fluorescence responses of the optimized assay configuration were tested over a range of UFH concentrations. Fig. S-3 illustrates the typical fluorescent responses seen from the assay device $(n=3)$. It can be seen that the fluorescence responses 45 demonstrated inversely proportional dose-dependent rates of residual FXa enzymatic activity, with decreasing rates of product formation at higher drug concentrations, illustrating the anti-FXa activity of the AT/UFH complex formed. At lower drug concentrations, the responses appeared to show some deviation ${ }_{50}$ from linearity, with an initial upward trend, suggesting enzyme activity was increasing over this period. After approximately $43 \mathrm{~s}$ and $55 \mathrm{~s}$, respectively, 0 and $0.2 \mathrm{U} / \mathrm{ml}$ heparin curves appeared to plateau. This is in part due to the reaching of the upper signal range achievable with the instrumental set up, but may also have 55 a contribution from substrate limitation. Dosages above $0.6 \mathrm{U} / \mathrm{ml}$ had significantly titrated out all of the available FXa, with $1 \mathrm{U} / \mathrm{ml}$ showing little change over background levels.

Various methods can be employed to analyze the responses from these types of assays, including rates of change and 60 responses at fixed time points. The $\log$ of the fluorescence responses at 30, 60 and $90 \mathrm{~s}$ were analyzed (Fig. 5 and Table S1). Fluorescence at 30 and $90 \mathrm{~s}$ returned $R^{2}$ values of 0.99 and 0.93 , with slopes of -0.915 and -1.205 , respectively. However, the regression at $60 \mathrm{~s}$ yielded an $\mathrm{R}^{2}$ of 0.97 and a slope of -1.12 . ${ }_{65}$ Assay measurements performed at $60 \mathrm{~s}$ were shown to be capable of measuring UFH in the range of 0 to $0.8 \mathrm{U} / \mathrm{ml}$ with intra-assay CVs of $<15 \%(n=3)$.

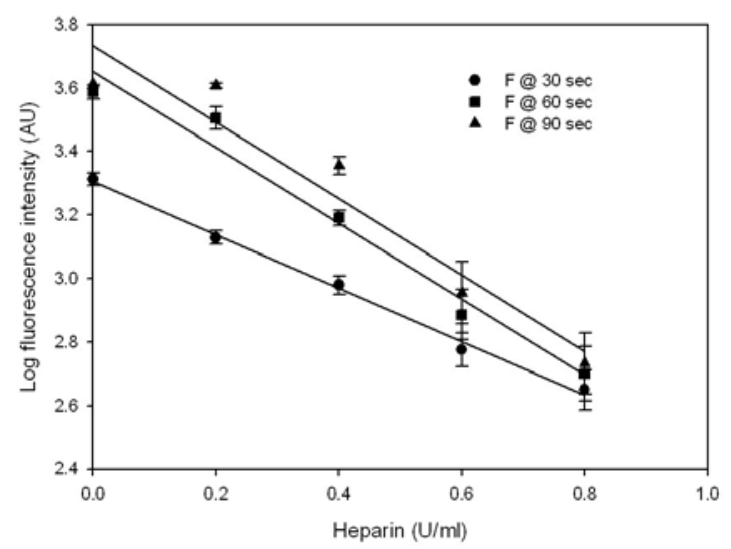

Fig. 5: Linear regression analysis of fluorescent responses at 30, 60 and 7090 seconds.

Two LMWH anticoagulants (tinzaparin and enoxaparin) were also tested on the anti-FXa microfluidic device and were analyzed along with UFH (Fig. 6). Linear regression analysis 75 with enoxaparin returned an $\mathrm{R}^{2}$ value of 0.98 with a linear correlation of $\mathrm{y}=-0.945+3.659$, while analysis of tinzaparin yielded an $R^{2}$ value of 0.96 with a linear correlation of $y=-0.789$ +3.637 . Statistical analysis was performed on the logarithmically transformed datasets to assess intra-assay variability. When tested 80 with enoxaparin-spiked plasmas a statistically sensitive range of 0 to $0.6 \mathrm{U} / \mathrm{ml}$ was achieved with CVs of $<11 \%$, while the limit of detection was $0.8 \mathrm{U} / \mathrm{ml}$ for plasma samples containing tinzaparin, with CVs of $<12 \%$. 


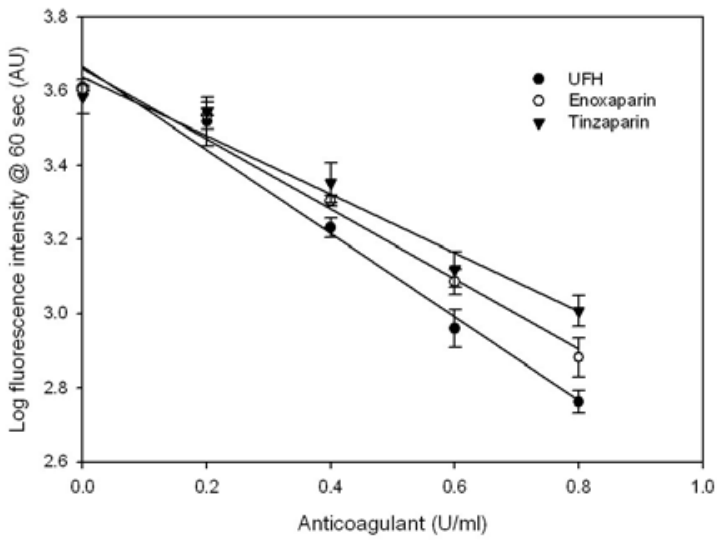

Fig. 6: Dose-response curves of human plasma spiked with UFH, enoxaparin and tinzaparin in the microfluidic anti-FXa assay device $(n=3)$.

\section{${ }_{5}$ Correlation of anti-Xa device with standard assays}

For validation purposes, the microfluidic assay device was correlated with both a fluorogenic microtitre plate-based anti-FXa assay as previously described by Harris et al. ${ }^{9}$ and with the 10 commercial Biophen ${ }^{\circledR}$ chromogenic assay from Hyphen BioMed (Neuville-Sur-Oise, France) (Fig. 7). A linear correlation was observed between the device and the fluorescent assay in the plate for plasma samples spiked with UFH, with an excellent $\mathrm{R}^{2}$ value of 0.99 (Fig. 7A). However, correlations of the device and 15 the fluorogenic plate-based assay with tinzaparin and enoxaparin (Fig. 7C, 7E) resulted in sigmoidal correlations $\left(\mathrm{R}^{2}=0.99\right)$.

Correlations similar to that seen between with the fluorogenic plate-based assay were also observed with the chromogenic assay. UFH plasma samples again resulted in a linear correlation 20 between the device and the chromogenic assay with an $\mathrm{R}^{2}$ value of 0.98 (Fig. 7B). For both LMWHs tested in the chromogenic assay, the correlations with the device also had a sigmoidal relationship $\left(\mathrm{R}^{2}=0.99\right)($ Fig. $7 \mathbf{D}, \mathbf{7 F})$. This indicates an increased sensitivity of the microfluidic assay device at intermediate ${ }_{25} \mathrm{LMWH}$ concentrations compared to the standard assays. Although the reason for this is not clear, the linear correlations for UFH suggest a combination of both mechanistic factors relating to the pharmacokinetics of the drugs and their interplay with the kinetics of the microfluidic assay device. Nonetheless, 30 correlations between the microfluidic device and both chromogenic and fluorogenic assays were achieved.

A point-of-care device based on the anti-Xa assay is not currently available so comparisons on levels of sensitivity and precision for this device can really only be drawn with clot-based 35 devices for heparin measurement currently on the market. The aPTT is recommended for monitoring heparin therapy. However, there are serious limitations that accompany this assay in terms of the measurement range and the inter-laboratory variability. ${ }^{25}$ For example, clinically and statistically significant differences were 40 observed between a point-of-care aPTT assay and a laboratorybased aPTT assay used to monitor patients on heparin therapy. ${ }^{26}$ Despite its disadvantages, the aPTT remains the most reliable and readily available test for clinicians, who will continue to use it until the emergence of a more accurate diagnostic test.

45 While many analysers exist and have been researched in the literature, the Hemochron ${ }^{\circledR}$ systems are the most widely accepted and commonly used, particularly for the measurement of aPTT. The Hemochron ${ }^{\circledR}$ system for aPTT measurement reports linearity with heparin up to $1.5 \mathrm{U} / \mathrm{ml}$, at intervals of $0.25 \mathrm{U} / \mathrm{ml}$ and CVs of ${ }_{50}<10 \% .{ }^{27}$ The Cascade ${ }^{\circledR}$ aPTT system from Helena Biosciences reports linearity up to $0.5 \mathrm{U} / \mathrm{ml}$ with an $\mathrm{R}^{2}$ of 0.98 , with intra and intervariability at $<3 \%$ for normal and abnormal samples. A correlation of 0.72 with the anti-Xa chromogenic assay is also reported on the company datasheet. ${ }^{28}$ In the current study we 55 observed linearity up to $0.8 \mathrm{U} / \mathrm{ml}$ with the anti-Xa device for UFH, enoxaparin and tinzaparin, with concentrations tapering off at $1 \mathrm{U} / \mathrm{ml}$.

When the aPTT is compared to other clotting tests for heparin poor correlations are often observed, due to the variable 60 responsiveness of commercial aPTT reagents to heparin. ${ }^{2}$ In terms of comparative studies, one research group compared bedside aPTT with laboratory aPTT using patients on heparin, with correlations varying from 0.13 to $0.67 .{ }^{29}$ Chavez et al. ${ }^{30}$ compared the CoaguChek ${ }^{\mathrm{TM}}$ Pro DM with core laboratory ${ }_{65}$ facilities for CPB (cardiopulmonary bypass) patients that received heparin therapy prior to surgery and a linear correlation $\left(\mathrm{R}^{2}=0.83\right)$ between the two assays was achieved. These findings were corroborated to a certain degree by Ferring et al. ${ }^{31}$ who reported poor agreement with patients after surgery but better 70 agreement with healthy volunteer and control patient samples. In their study the anti-Xa assay also provided the best correlation with heparin dosage compared to point-of-care aPTT and central laboratory aPTT. In our study linear correlations $\left(\mathrm{R}^{2}\right.$ of 0.99$)$ between the device and both plate-based assays were observed 75 with control plasma samples containing UFH.

The prothrombinase-induced clotting time assay $(\mathrm{PiCT})$ is a point-of-care clotting time assay, sensitive to inhibitors of both thrombin and Xa. Calatzis et al. ${ }^{32}$ compared the PiCT with both aPTT and anti-Xa chromogenic assays for a range of 80 anticoagulants. A non-linear response was observed with patients on fondaparinux, a synthetic inhibitor of FXa, while an almost linear response was achieved with patients on UFH, dalteparin, and enoxaparin. When comparing our device to the established chromogenic assay with samples spiked with LMWHs, we also 85 observed non-linear correlations. However, using a sigmoidal treatment, excellent correlations of 0.99 were observed. This nonlinearity with LMWH has also been reported by Coppell et al. ${ }^{33}$ who demonstrated a loss of linearity at LMWH concentrations above $0.5 \mathrm{U} / \mathrm{ml}$ when comparing TEG with a conventional aPTT 90 clotting assay. 

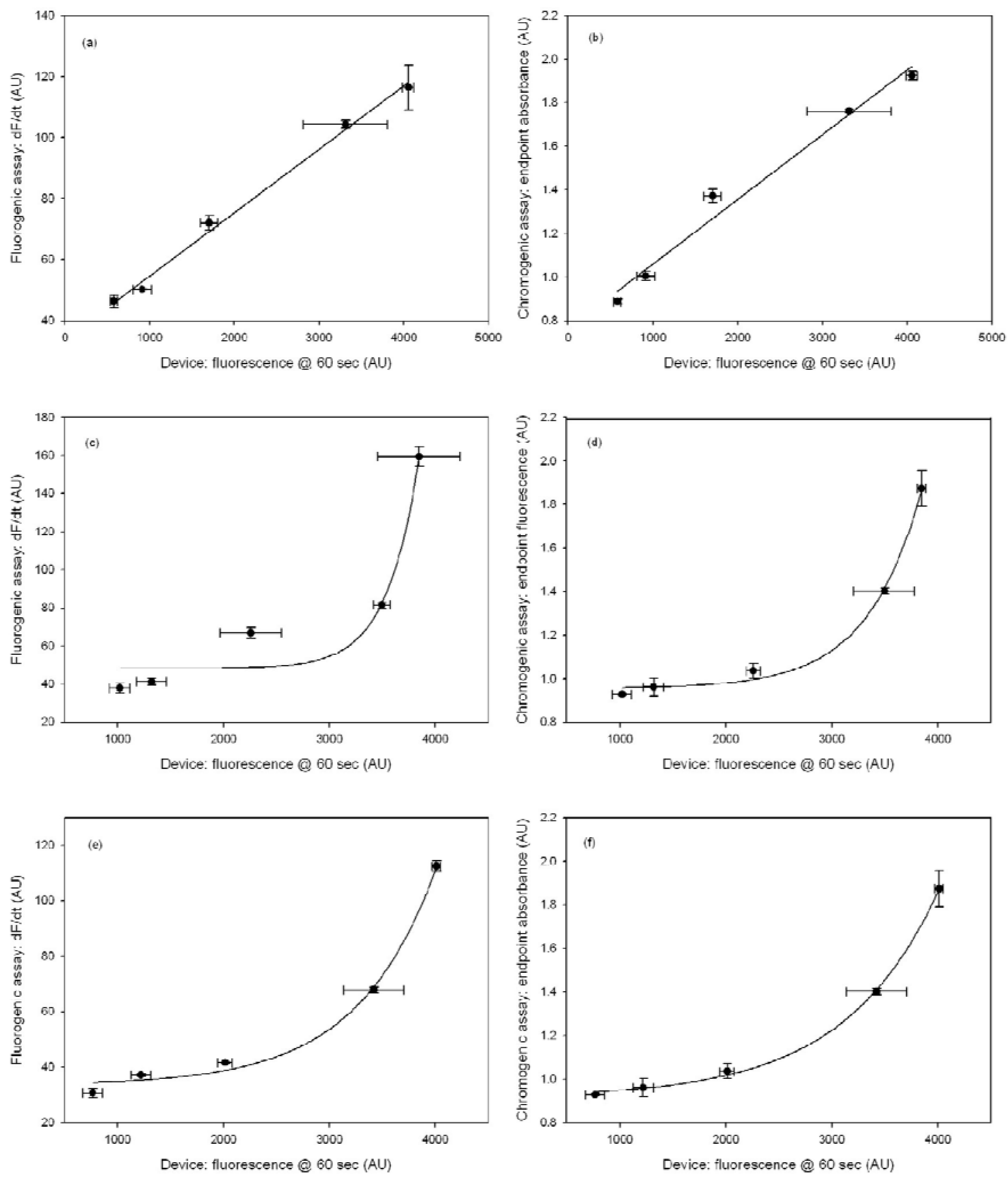

Fig. 7: Correlations of the anti-Xa assay in the microfluidic device with the anti-FXa plate-based assay and the Biophen ${ }^{8}$ chromogenic assay for UFH (ab), tinzaparin (c-d), and enoxaparin (e-f) (n=3).

\section{${ }_{5}$ Conclusions}

The ability to measure the concentration of both unfractionated and low molecular weight heparin anticoagulant drugs in plasma was demonstrated using a polymer microfluidic device with integrated anti-FXa assay. Fluorescent measurement after $60 \mathrm{~s}$ 10 demonstrated assay ranges from 0 to $0.6 \mathrm{U} / \mathrm{mL}$ for enoxaparin and 0 to $0.8 \mathrm{U} / \mathrm{mL}$ for UFH and tinzaparin. The assay platform was shown to correlate well against both chromogenic and fluorogenic anti-FXa assays performed in microtitre plates. Such

a device could be used at the point-of care for monitoring anti15 coagulant therapies.

\section{Acknowledgements}

${ }_{20}$ This work was supported by Enterprise Ireland under Grant No. TD/2009/0124. 


\section{Notes and references}

${ }^{a}$ Biomedical Diagnostics Institute, National Centre for Sensor Research, Dublin City University, Dublin 9, Ireland. Tel: + 003531 7006332; Email: leanne.harris@dcu.ie

$5^{b}$ School of Mathematics and Physics, Queen's University Belfast, Belfast, BT7 1NN, Northern Ireland, UK. E-mail: P.Rainey@ee.qub.ac.uk

${ }^{c}$ CIC microGUNE, Microfluidics Unit, Polo Innovación Garaia, 20500 Mondragón, Spain.E-mail: vanessa.castro.lopez@gmail.com

${ }^{d}$ Haemostasis Research Group, Institute of Molecular Medicine, St 10 James's Hospital, Trinity College, Dublin 8, Ireland. Tel: + 003531 4164844; E-mail: jodonne@tcd.ie

${ }^{e}$ Department of Applied Sciences, University of the West of England, Frenchay Campus, Coldharbour Lane, Bristol, BS16, 1QY, UK. Fax: + 0044 1173442904; Tel: + 0044 1173282147; E-mail:

15 tony.killard@uwe.ac.uk

$\dagger$ Electronic Supplementary Information (ESI) available: See DOI: $10.1039 / \mathrm{b} 000000 \mathrm{x}$

\section{${ }_{20} \uparrow$ S-1 Experimental section}

Fluorogenic and chromogenic assay correlations

Absorbance and fluorescence measurements were performed in an Infinite M200 spectrophotometric microplate reader (Tecan

${ }_{25}$ Group Ltd, Männedorf, Switzerland) equipped with a UV Xenon flashlamp. Flat, black-bottom 96-well polystyrol FluorNunc ${ }^{\mathrm{TM}}$ microplates from Thermo Fisher Scientific (Roskilde, Denmark) were used for fluorescence measurements. Flat, transparent 96well Greiner ${ }^{\circledR}$ microplates from Greiner Bio-One 30 (Gloucestershire, United Kingdom) were used for absorbance measurements. All measurements for the fluorogenic anti-FXa assay and the chromogenic assay were carried out in reconstituted citrated human pooled plasma. Pooled commercial plasma samples were spiked with pharmacologically relevant 35 concentrations $(0-0.8 \mathrm{U} / \mathrm{ml})$ of therapeutic anticoagulants including UFH, enoxaparin, and tinzaparin.

For the fluorogenic assay, FXa and Pefafluor FXa fluorogenic substrate concentrations were previously optimized as $4 \mathrm{nM}$ and $0.9 \mu \mathrm{M}$, respectively. ${ }^{9}$ Each well contained $6 \mu \mathrm{l}$ of $100 \mathrm{mM}$ ${ }_{40} \mathrm{CaCl}_{2}, 44 \mu \mathrm{l}$ of pooled plasma, and $50 \mu \mathrm{l}$ of $\mathrm{FXa}$. The reaction was started by adding $50 \mu \mathrm{l}$ of Pefafluor FXa fluorogenic substrate. Samples within wells were mixed with the aid of orbital shaking at $37{ }^{\circ} \mathrm{C}$ for $30 \mathrm{~s}$. Immediately after shaking, fluorescence measurements were recorded at $37^{\circ} \mathrm{C}$ for $60 \mathrm{~min}$,

45 with a $20 \mu$ s integration time. Fluorescence excitation was at 342 $\mathrm{nm}$ and emission was monitored at $440 \mathrm{~nm}$, corresponding to the excitation/emission wavelengths of the 7-amino-4methylcoumarin (AMC) fluorophore. All the measurements were carried out in triplicate.

50 The Biophen ${ }^{\circledR}$ Heparin chromogenic assay from Hyphen BioMed (Neuville-Sur-Oise, France) was carried out according to the manufacturer's instructions as follows: each well contained $50 \mu \mathrm{l}$ of plasma and $50 \mu \mathrm{l}$ of antithrombin (AT). To this, $50 \mu \mathrm{l}$ of FXa was added. The reaction was started by adding $50 \mu 1$ of FXa ${ }_{55}$ specific chromogenic substrate. Samples within wells were mixed within the spectrophotometer by orbital shaking at $37^{\circ} \mathrm{C}$ for $30 \mathrm{~s}$. Immediately after shaking, absorbance measurements were recorded at $37{ }^{\circ} \mathrm{C}$ for $60 \mathrm{~min}$, at $10 \mathrm{~s}$ intervals. Absorbance was measured at $405 \mathrm{~nm}$ and all measurements were performed in 60 triplicate.

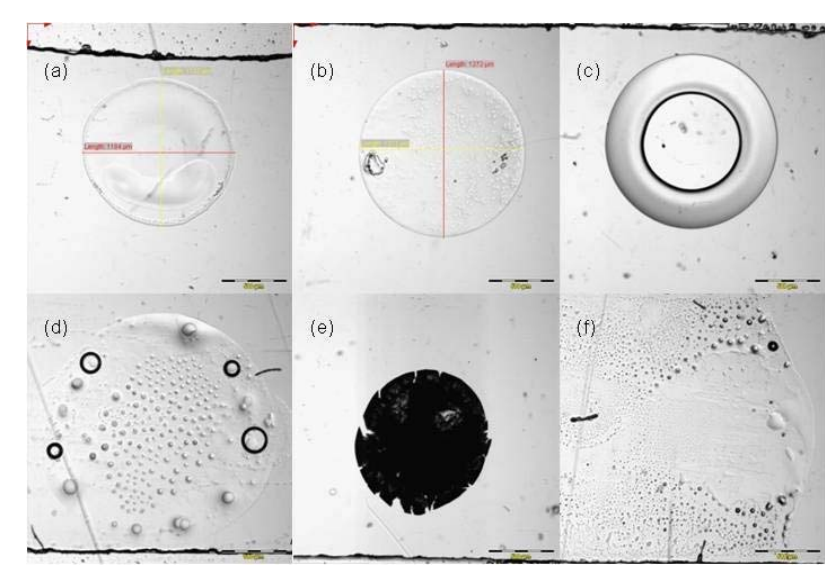

Fig. S-1: Morphology of fluorogenic substrate deposited in a range of buffers (x 100 magnification): (a) $10 \mathrm{mM}$ HEPES buffer (b) $0.01 \mathrm{mM}$ HEPES buffer (c) StabilCoat buffer (d) $2 \%$ Tween 20 (e) $10 \%$ PEG 653400 (f) $1 \%$ Triton X-100.

\section{S-2 Results and discussion \\ Optimization of substrate deposition}

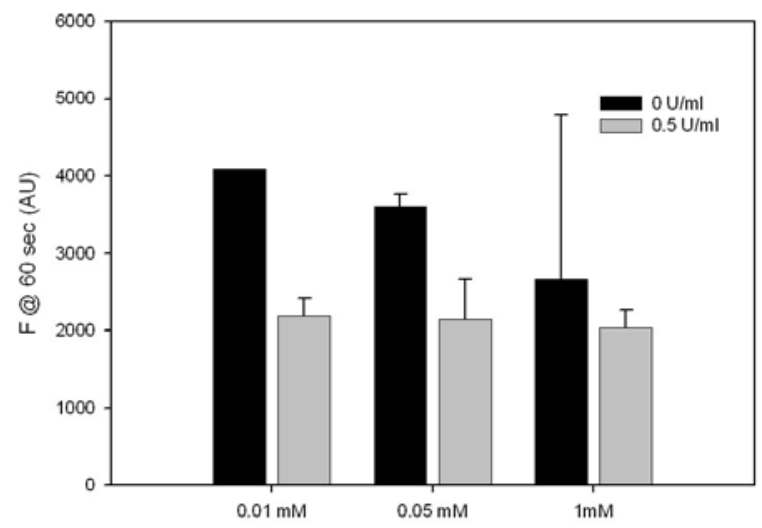

Fig. S-2: Comparison of the fluorescence responses of unheparinised (0 $70 \mathrm{U} / \mathrm{ml})$ and heparinised $(0.5 \mathrm{U} / \mathrm{ml})$ plasmas in microfluidic devices with fluorogenic substrate prepared in $0.1,0.05$, and $0.01 \mathrm{mM}$ HEPES buffer $(n=3)$. 


\section{Anticoagulant calibrations}

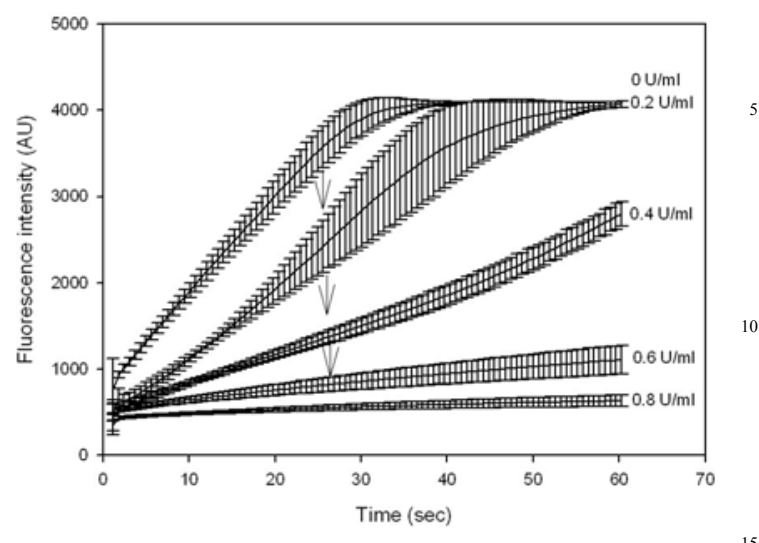

Fig. S-3: Fluorescence response profiles of human plasmas in the antiFXa assay device supplemented with concentrations of UFH from 0 to 0.8 $\mathrm{U} / \mathrm{ml}(\mathrm{n}=3)$.

20 Table S-1: Comparison of data analysis methodologies based on linear regression

\begin{tabular}{c|c|c}
\hline $\begin{array}{c}\text { Time of fluorescence } \\
\text { measurement (s) }\end{array}$ & $\begin{array}{c}\text { Regression } \\
\text { equation }\end{array}$ & $\mathbf{R}^{2}$ value \\
\hline 30 & $\mathrm{y}=-0.915 \mathrm{x}+3.427$ & 0.99 \\
60 & $\mathrm{y}=-1.124+3.665$ & 0.97 \\
90 & $\mathrm{y}=-1.110+3.728$ & 0.93 \\
\hline
\end{tabular}

1. P. M. Mannucci and M. Franchini, Ann. Med., 2011, 43, 116123.

25 2. J. Hirsh and R. Raschke, Chest, 2004, 126, 188S-203S.

3. T. Baglin, T. W. Barrowcliffe, A. Cohen and M. Greaves, Br. J. Haematol., 2006, 133, 19-34.

4. S. Kitchen, Br. J. Haematol., 2000, 111, 397-406

5. C. M. Lehman and E. L. Frank, Lab Med., 2009, 40, 47-51.

${ }_{30} 6$. V. Laux, E. Perzborn, S. Heitmeier, G. von Degenfeld, E. Dittrich-Wengenroth, A. Buchmüller, C. Gerdes and F. Misselwitz, Thromb. Haemost., 2009, 102, 892-9.

7. S. Middeldorp, Thromb. Res., 2008, 122, 753-762.

8. H. Bounameaux and P. De Moerloose, J. Thromb. Haemost., 2004, 2, 551-554.

9. L. F. Harris, V. Castro-López, N. Hammadi, J. S. O’Donnell and A. J. Killard, Talanta, 2010, 81, 1725-30.

10. V. Castro-López, L. F. Harris, J. S. O’Donnell and A. J. Killard, Anal. Bioanal. Chem., 2011, 399, 691-700.

40 11. A. Holbrook, S. Schulman, D. M. Witt, P. O. Vandvik, J Fish, M. J. Kovacs, P. J. Svensson, D. L. Veenstra, M. Crowther and G. H. Guyatt, Chest, 2012, 141, e152S$84 \mathrm{~S}$.

12. C. F. Weber and K. Zacharowski, Dtsch. Arztebl. Int., 2012, 109, 369-75.

13. G. M. Whitesides, Nature, 2006, 442, 368-373.

14. V. Linder, Analyst, 2007, 132, 1186-1192.

15. M. M. Dudek, T. L. Lindahl and A. J. Killard, Anal. Chem. 2010, 82, 2029-2035.

50 16. A. Bhattacharyya and C. M. Klapperich, Anal. Chem., 2006, 78, 788-792.

17. C. Jonsson, M. Aronsson, G. Rundstroem, C. Pettersson, I. Mendel-Hartvig, J. Bakker, E. Martinsson, B. Liedberg,
B. MacCraith, O. Oehman and J. Melin, Lab Chip, 2008, 8, 1191-1197.

18. L. F. Harris, V. Castro-López, P. V. Jenkins, J. S. O’Donnell and A. J. Killard, Thromb. Res., 2011, 128, e125-9.

19. H. L. J. Messmore, J. Fareed, J. Kniffin, G. Squillaci and J. Walenga, Ann. N. Y. Acad. Sci., 1981, 370, 785-797.

${ }_{60}$ 20. J. Fareed, H. L. Messmore and E. W. Bermes, Clin. Chem., 1980, 26, 1380-1391.

21. A. N. Teien, M. Lie and U. Abildgaard, Thromb. Res., 1976, 8, 413-416.

22. L. Brown, T. Koerner, J. H. Horton and R. D. Oleschuk, Lab Chip, 2006, 6, 66-73.

23. V. Gubala, L. F. Harris, A. J. Ricco, M. X. Tan and D. E. Williams, Anal. Chem., 2012, 84, 487-515.

24. D. J. Perry, D. A. Fitzmaurice, S. Kitchen, I. J. Mackie and S. Mallett, Br. J. Haematol., 2010, 150, 501-514.

70 25. J. W. Eikelboom and J. Hirsh, Thromb. Haemost., 2006, 96, $547-552$.

26. A. D. Douglas, J. Jefferis, R. Sharma, R. Parker, A. Handa and J. Chantler, Angiology, 2009, 60, 358-361.

27. ITC (International Technidyne Corporation), Whole Blood Microcoagulation System Operator's Manual.

28. Helena Laboratories, Cascade ${ }^{\circledR}$ POC aPTT Datasheet, 2021.

29. M. A. Smythe, J. M. Koerber, S. J. Westley, S. N. Nowak, R. L. Begle, M. Balasubramaniam and J. C. Mattson, Coag. Transfus. Med., 2001, 115, 148-155.

30. J. J. Chavez, J. S. Weatherall, S. M. Strevels, F. Liu, C. C. Snider and R. C. Carroll, J. Clin. Anest., 2004, 16, 7-10.

31. B. R. Ferring, M. Reber, G, P. de Moerloose, P. Merlani and M. Diby, Can. J. Anaesth, 2001, 48, 1155-1160.

32. A. Calatzis, D. Peetz, S. Haas, M. Spannagl, K. Rudin and M. Wilmer, Am. J. Clin. Pathol., 2008, 130, 446-54.

33. J. A. Coppell, U. Thalheimer, A. Zambruni, C. K. Triantos, A. F. Riddell, A. K. Burroughs and D. J. Perry, Blood Coagul. Fibrinolysis, 2006, 17, 97-104. 